\title{
Serbest Zaman Doyumunun Mutluluk Üzerindeki Etkisinde Cinsiyetin Düzenleyici Rolü
}

\author{
Pınar Güzel Gürbüza, Özge Yavaş Tez ${ }^{\mathrm{b}}$, Melike Esentaşc
}

Özet

Araştırmada Türkiye'de turizm bölgelerinde faaliyet gösteren tur şirketlerinden paket satın alan yerli turistlerin katıldıkları serbest zaman etkinliklerine ilişkin deneyimlerinden elde edilecek doyumun mutluluk üzerindeki etkisinde cinsiyet değişkeninin düzenleyici rolü olup olmadığının ortaya çıkarılması amaçlanmıştır. Bu doğrultuda araştırmaya 340 birey katılmıştır. Araştırmada katılımcıların demografik özelliklerini belirlemek amacıyla kişisel bilgi formu ile birlikte, Serbest Zaman Doyum Ölçeği ve Oxford Mutluluk Ölçeği uygulanmıştır. Yapılan analizler neticesinde serbest zaman doyumu ile mutluluk arasında nedensel ilişkinin olduğu ve p değerinin istatistiksel olarak anlamlı olduğu bulgusuna ulaşılmıştır. Düzenleyici etki analizi sonucunda ise "serbest zaman doyumu-estetik ile mutluluk" ilişkisinde ve "serbest zaman doyumu-rahatlama ile mutluluk" ilişkisinde kadın ve erkekler açısından anlamlı farklılıkların olduğu belirlenmiştir.
Anahtar Kelimeler

Serbest zaman

Mutluluk

Serbest zaman doyumu

Makale Hakkında

Geliş Tarihi: 29.03.2020

Kabul Tarihi: 25.12.2020

Doi: 10.18026/cbayarsos.711055

\section{Moderator Role of Gender in the Effect of Leisure Satisfaction on Happiness}

\begin{abstract}
It was aimed to reveal whether moderator role of gender in the effect of leisure satisfaction on happiness existed which would be acquired from the experiences of domestic tourists regarding leisure activities they participated after buying packet tours from the tour operators operating in tourism regions of Turkey. Accordingly, the research included a total of 340 participants. In order to determine the demographic characteristics of the participants, the Leisure Satisfaction Scale and the Oxford Happiness Scale were applied along with the personal information form. As a result of the analyses, it was found that there was a causal relationship between leisure satisfaction and happiness and the p-value was statistically significant. On the other hand, as a result of moderator impact analysis, it was determined that there were significant differences in terms of females and males in the relationship of "leisure satisfaction-aesthetics and happiness" and in the relationship of "leisure satisfaction-relaxation and happiness".
\end{abstract}

Keywords
Leisure
Happiness
Leisure satisfaction

\section{About Article}

Received: 29.03.2020

Accepted: 25.12.2020

Doi: 10.18026/cbayarsos.711055 


\section{Giriş}

İnsanlığın var oluşu birtakım ihtiyaçları ortaya çıkarmıştır. Bu ihtiyaçlar bireyin yaşamını sürdürebilmesi açısından daha çok temel ihtiyaçların karşılanması olarak düşünülse de yaşamın farklı alanlarında farklı şekillerde de farklı ihtiyaçlara gereksinim duyulmaktadır. Özellikle sanayileşme ve kentlileşme ile doğadan koparılan insan bedensel ve psikolojik olarak yenilenme ihtiyacı duymaktadır ve bu ihtiyacını da doğa ile iç içe olarak kendini gerçekleştirebileceği birtakım serbest zaman deneyimleri yaşayarak karşılamak ister. Doğa ile insan arasındaki bu etkileşim dolaylı olarak etkinliklerin gerçekleştirildiği turizm destinasyonlarını etkileyerek insanların bu alanlara yönelmelerini zorunlu hale getirmiştir (Aslan, 1993). Bireylerin turizm alanlarında serbest zamanlarını değerlendirmek amacıyla gerçekleştirdikleri bu etkinlikler literatürde "rekreasyon" kavramı altında birleşmektedir ve bu kavram en basit hali ile bireylerin kendileri için ayırdıkları bir zaman diliminde dinlenmek, yenilenmek, özgürlük ve iyi olma hissi yaşayabileceği ve içsel olarak doyuma ulaşabileceği verimlilik ve gönüllük esasına dayanan etkinlikler içerisinde yer almaları olarak tanımlanmıştır (Kılbaş, 2001; Luetkens, 2004).

Rekreasyon ile macera turizmi günümüzde serbest zaman etkinliklerinin deneyimlenmesinde geniş yer tutan iki kavramdır. Doğada gerçekleştirilen rekreatif etkinliklerin önemli bir kısmının macera turizmiyle iç içe olduğu düşünülse de rekreatif etkinlikler, uygun durum ve koşullar sağlandığında finansal açıdan hiçbir masraf yapmadan var olan kaynaklarla yapılabilecek bir serbest zaman değerlendirme biçimi olduğu (Tangeland ve Aas, 2011); doğa temelli turizmin özel bir alanı olarak görülen macera turizminin ise etkinliğin yapılacağ ortam, zaman ve finansal açıdan katılımcıyı zorlayabilecek bir takım ihtiyaçların karşılanmasını zorunlu kılan ve bu bakımdan kendine has özellikleri olduğu unutulmamalıdır (Moore, Cushman ve Simmons, 1995; Bovy ve Lawson, 1998; Hacıŏlu, Gökdeniz ve Dinç, 2003). Özellikle Türkiye'de 1980 yılından sonra hareketlenerek bir sektör haline gelen turizm bölgeleri yerli ve yabancı turistler açısından popüler olamaya başlamıştır. Türkiye bu noktada içerisinde bulunduğu coğrafi konum, kültürel alt yapısı ve mimari özellikleri sebebi ile diğer ülkelere göre avantajlı konumdadır. Bu özelliklerin doğru yapılandırılması ve kullanılması ile ülkenin çeşitli bölgelerinde doğa, akarsu, yat, mağara gibi çeşitli turizm etkinlikleri gerçekleştirilmektedir (Ardahan, 2003).

Doğayı deneyimlemek ve keşfetmek isteyen bireyler bu arzularına ulaşmak için bir yola çıkmaktadır. Bu yol bazen şehir yaşamından uzaklaşarak yalnız kalmak, doğa ile bütünleşmek olurken bazen de bir kaçış yolu olarak karşımıza çıkmaktadır (Bell, 2001). Bireylerin serbest zamanlarını değerlendirmek için gittikleri bu yolda seçimini yaptı̆̆ etkinlik deneyimi sonucunda elde edilmesi arzulanan bir içsel haz yani doyumun ortaya çıkması rekreasyon tanımlarının ortak bileşenleri olarak görülmektedir. Peki bahsedilen bu şey yani doyum nedir? Doyum; davranışlarımızı yönlendiren ve doğrudan etkileyen ihtiyaçların bilinçli ya da farkında olmadan karşılanması ile ölçülen bir derece olarak tanımlanabilirken; serbest zaman doyumu, bireylerin serbest zaman etkinliklerini değerlendirme biçimlerinde anahtar rol oynayan ve bireyin etkinlik deneyimini algılama biçimi olarak karşımıza çıan pozitif hisler yani mutlu olma hissi üzerine kurulmuş bir kavramdır (Gökçe, 2008).

"Mutlu olma hissi" ya da "mutluluk" nedir? Günlük hayatımızda sıklıkla kullandığımız ancak açıklaması hayli zor olan bir kavramdır. Birçoğumuz mutluluğu aslında neşeli olma, 
heyecanlanma, memnuniyet şeklinde ifade etmektedir. Ancak ifade edilen hiçbir sözcük mutluluğu tam olarak yansitamaz (Marar, 2004). Peki mutluluk, şans eseri ya da rastlantı sonucu ortaya çıkan bir şey midir? Mutluluk bilinçli bir şekilde aranılmaz. Şöyle ki ayna karşısında kendinize mutlu olup olmadığınızı soralım. İşte o an bize aynadan yansıyan şey bir dakika öncesinden farklılaşır yani "mutluluğunuz sona erer". Mutluluk basit bir ifade ile bireyin zihnini özel olarak bir hazırlık sürecine soktuğu, geliştirdiği ve savunduğu bir durumdur. Yaşamınızı bir süzgeçten geçirin ve unutamadığınız bazı anları bir film şeridi gibi aklınızdan geçirin. Bu anlar sizin en çok yorulduğu, zor şeylerin üstesinden geldiği, zihin ve beden bütününün sınırlarını zorladığı anlar. İşte bu anlar sizin en iyi en güzel anlarınızdır. Küçük bir çocuk için bir kulenin tepesine titreyen elleriyle son parçayı koyduğu an; bir sporcu için kendi rekorunu kırdığ bu anlar aslında en çok zorlanılan, acı çekilen, tükenme noktasına gelinen anlardır. Ancak o anlarda bireyler fiziksel ve ruhsal olarak bütünleşir ve akışa geçerler ve o "an" in içinde kaybolurlar ve bunun sonucunda da içsel olarak doyuma ulaşarak ve mutlu olurlar. Bu süreçte hiç kimse etkinlik içerisinde yaşanan kötü hislerden bahsetmez aksine bu anlar keyif aldığımız yüzümüzde tebessüm ettiren anlar olarak hatıralarımızda yer edinir. İşte mutluluğun tarifi budur (Mihaly, 2005). Mutluluğun tanımlamak zordur. Veenhoven (2000) mutluluğa farklı bir bakış açısı ile yaklaşarak mutluluğun hayatın akışı içerisinde ortaya çıkan kısa vadeli, anlık duygu durumu olarak tanımlayarak bunun yaşanması gereken bir deneyim olduğunu ifade etmiştir.

Mutluluğun kısa vadeli olduğu düşünüldüğünde doğayı deneyimlemek isteyen katılımcıların gerçekleştirdikleri etkinliklerde belirli bir zaman aralığında ve anlıktır. Bu noktada bireyin yaşadığı anlarda kendine özeldir. Birey o an içerisinde bulunduğu duruma bağlı olarak bir etkinlik seçer ve seçtiği bu etkinlik sonucunda da bir takım kazanımlar elde eder. Bireyin seçmiş olduğu etkinlik deneyimine ilişkin kazanımlar olumlu olduğunda birey içsel olarak belirli bir doyum düzeyine ulaşır ve bunun sonucunda da kendini mutlu hisseder. Bu da bireyleri katılım gösterdikleri o etkinlik deneyimini tekrar yaşama isteğini arttırır ya da benzer etkinliklere yöneltir (Gökçe, 2008).

Doğa gerçekleştirilen serbest zaman deneyimlerinin ve deneyimden elde edilecek çıtıların bireye özgü olması doyum ve mutluluk düzeyinin de farklılaşmasında etken olabileceği düşünülmektedir. Bu sebeple araştırmada özellikle turizm amaçlı katılımın yoğun olduğu bölgelerde tur programlarına katılan yerli turistlerin serbest zaman deneyimlerinden elde edilecek doyumun mutluluk üzerindeki etkisinde cinsiyet değişkeninin düzenleyici rolü olup olmadığı incelenmiştir.

\section{Yöntem}

\section{Evren ve Örneklem / Çalışma Grubu / Katılımcılar}

Araştırma, Türkiye'de turizm bölgelerinde faaliyet gösteren tur şirketlerinden paket satın alan (uçurtma sörfü, yamaç paraşütü, aletli dalış, rafting, bungee jumping, rüzgar sörfü) yaşları 15 ile 58 arasında değişen, 191 kadın (Ortyaş=28,76 $\pm 76,24$ ) ve 149 erkek (Ortyaş=30.72 \pm 7.49 ) olmak üzere toplam 340 yerli turist (Ortyaş=29,62 $\pm 6,88$ ) oluşturmuştur. Katılımcılara, olasılıklı örnekleme tekniklerinden kolayda örnekleme yöntemi kullanılarak ulaşılmıştır. 


\section{Veri Toplama Araçları}

Araştırmada katılımcıların demografik özelliklerini belirlemek amacıyla kişisel bilgi formu ile birlikte, Serbest Zaman Doyum Ölçeği (SZDÖ) ile Oxford Mutluluk Ölçeği Kısa Formu (OMÖ-K) uygulanmıştır. Katılımcılara ölçekler, tur rehberleri aracılığı ile ulaşılarak doldurtulmuştur.

\section{Kişisel Bilgi Formu}

Araştırmada kişisel bilgi formu katılımcılarının demografik özelliklerini tespit etmek amacıyla kullanılmıştır. Kişisel bilgi formunda, cinsiyet, yaş, gibi sorular bulunmaktadır.

\section{Serbest Zaman Doyum Ölçeği (SZDÖ)}

Serbest Zaman Doyum Ölçeği, ilk olarak Beard ve Ragheb (1980) tarafından geliştirilmiş ve daha sonra Gökçe ve Orhan (2011) tarafından ölçeğin Türkçe geçerlik ve güvenirlik çalışması yapılarak ölçeğe ilişkin madde sayısı $24^{\prime}$ e indirilmiştir. Türkçe geçerlik ve güvenirlik çalışması yapılan SZDÖ; psikolojik "1-4", eğitimsel "5-8", sosyal “9-12", fiziksel "13-16", rahatlama "1720" ve estetik "21-24" olmak üzere toplam 6 alt boyuttan ve 24 maddedir. Ölçeğe ilişkin her alt boyutta 4 madde yer almaktadır. Ölçek 5'li Likert tipi derecelendirme biçiminde olup; "1" neredeyse hiç doğru değil, "2" nadiren doğru, "3" bazen doğru, "4" çoğu kez doğru, "5" neredeyse her zaman doğru şekildeki derecelendirme skalasına göre hesaplaması yapılmaktadir.

\section{Oxford Mutluluk Ölçeği Kısa Formu (OMÖ-K)}

Oxford Mutluluk Ölçeği, İlk olarak Hills ve Argyle (2002) tarafından 29 maddelik olarak geliştirilmiş ve daha sonra Doğan ve Çötok (2011) tarafından ölçeğin Türkçe geçerlik ve güvenirlik çalışması yapılarak tek faktör ve 8 maddeden oluşan kısa formu oluşturulmuştur. Ölçeğin derecelendirmesi " 1 ” hiç katılmıyorum, "2" katılmıyorum, “3” biraz katılıyorum, "4" katıliyorum, " 5 " tamamen katıllyorum şekildeki derecelendirme skalasına göre hesaplaması yapılmaktadır. Ölçeğin 1. ve 7. Maddelerinin hesaplaması yapılırken verilen cevaplar ters kodlanmalıdır. Ölçekten alınan yüksek puanlar bireylerin mutluluk düzeyinin arttığını göstermektedir.

\section{Verilerin Toplanması ve Analizi}

Araştırmaya ilişkin veriler, tur şirketlerinin rehberleri ile turizm destinasyonlarındaki eğitmenler aracılığı ile toplanmıştır. Ayrıca formlar elektronik ortama aktarılarak tur şirketlerine ait sosyal gruplarda online olarak paylaşılarak katılım göstermeleri sağlanmıştır. Veri toplama süreci sonunda doğa ve macera rekreasyonu katılımcıları üzerinden toplam 340 yerli turist katılımcısından geri dönüş alınmış ve veriler ilk olarak IBM SPSS 24 programına aktarılarak analiz için hazır aşamasına getirilmiş daha sonra AMOS 23 programında serbest zaman doyumu ve mutluluk değişkenleri arasındaki nedensellik ilişkileri yapısal eşitlik modeli ile test edilmiştir. Bu doğrultuda modelde bağımsız değişken (serbest zaman doyumu). Bağımlı değişken (mutluluk) ve düzenleyici değişken (cinsiyet) olarak alınmıştır. Yapısal eşitlik analizine geçilmeden önce her bir değişkenin açımlayıcı ve doğrulayıcı faktör analizleri yapılarak değişkenler modelin test edilmesi için hazırlanmıştır. 


\section{Araştırma Modeli ve Hipotezler}

Araştırmada yer alan serbest zaman doyumu ve mutluluk arasındaki etkileşimde literatürden destek alınarak teorik model oluşturulmuştur. Oluşturulan modelde "serbest zaman doyumu" değişkeninin "mutluluk" üzerinde etkisi olduğu ve cinsiyet değişkenin de her iki değişken üzerinde etkileşiminde düzenleyici rol üstlendiği düşünülmektedir. Araştırmaya ilişkin oluşturulan kavramsal model Şekil 1.de gösterilmiştir. Araştırmaya ilişkin kurulan modelde düzenleyici değişken $(\mathrm{W})$ cinsiyet, tahmin değişkeni $(X)$ serbest zaman doyumu, sonuç değişkeni (Y) mutluluk olarak alınmıştır.

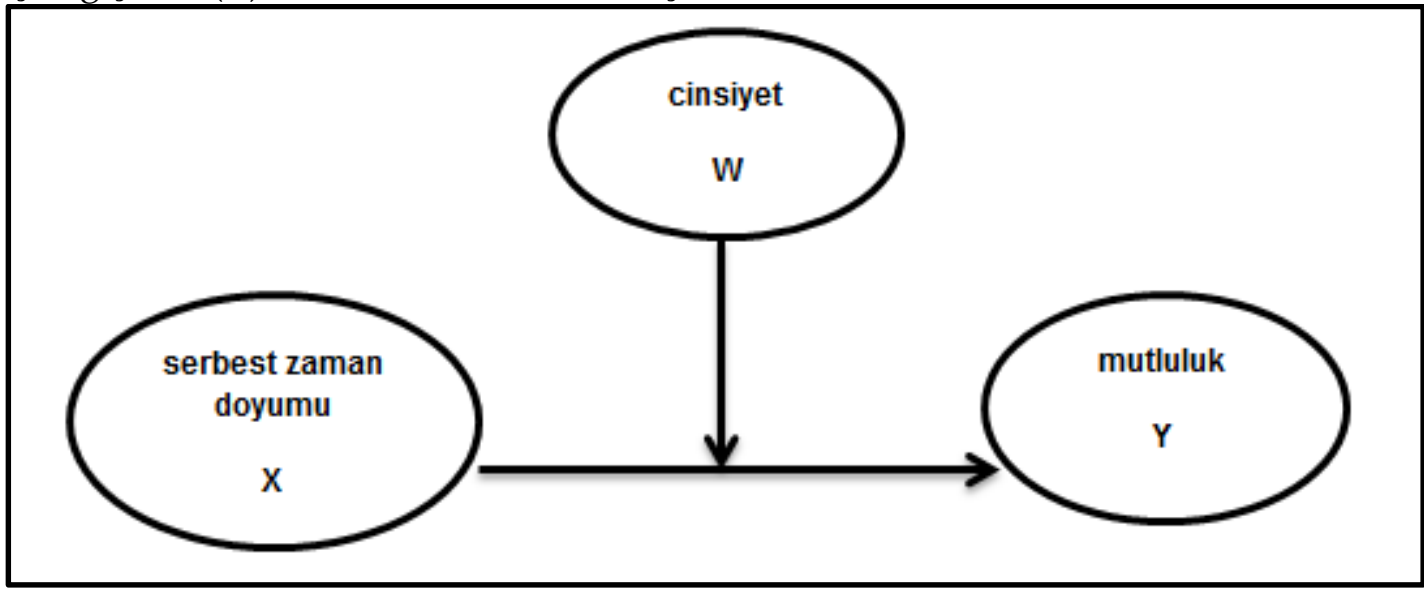

Şekil 1. Kavramsal Model

\section{Araştırma Hipotezleri}

Araştırma modeli çerçevesinde kurulan hipotezler aşağıdaki şekilde oluşturulmuştur.

H1: Serbest zaman doyumu mutluluğu anlamlı ve pozitif olarak etkiler.

H2: Serbest zaman doyumunun mutluluğa etkisi cinsiyete bağlıdır. Bu etki kadınlarda erkeklere oranla daha düşüktür.

\section{Araştırmada Kullanılan Ölçeklerin Güvenilirlik ve Geçerlilik Analizlerine İlişkin Sonuçlar}

Araştırma kapsamındaki ölçeklerin yapısal geçerliliğini tespit etmek amacıyla Doğrulayıcı Faktör Analizi (DFA) gerçekleştirilmiştir.

Serbest Zaman Doyumu ve Oxford Mutluluk ölçeklerinin her birisi için birinci düzey Doğrulayıcı Faktör Analizi (DFA) yapılmıştır. Araştırma kapsamında kullanılan ölçeklerin uyum indekslerine ilişkin sonuçlar Tablo 1 'de sunulmuştur.

Tablo 1- Standart Uyum İndeksleri ve DFA Analiz Sonucu Ölçeklere İlişkin Uyum İndeksleri

(Schumacher ve Lomax, 1996; Schermelleh, Engel ve Moosbrugger, 2003: 23-74).

\begin{tabular}{lllll}
\hline $\begin{array}{l}\text { Uyum } \\
\text { İndeksi }\end{array}$ & Mükemmel Uyum & Kabul Edilebilir Uyum & $\begin{array}{l}\text { Serbest } \\
\text { Zaman } \\
\text { Doyumu }\end{array}$ & $\begin{array}{l}\text { Oxford } \\
\text { Mutluluk }\end{array}$ \\
\hline $\mathbf{x}^{2} /$ sd & $0-3$ & $3-5$ & $\mathbf{2 . 4}$ & $\mathbf{2 . 4}$ \\
\hline CFI & $.95 \leq$ CFI $\leq 1.00$ & $.90 \leq \mathrm{CFI}<.95$ & $\mathbf{. 9 3}$ & $\mathbf{. 9 7}$ \\
\hline GFI & $.90 \leq$ GFI $\leq 1.00$ & $.85 \leq \mathrm{GFI}<.90$ & $\mathbf{. 8 8}$ & $\mathbf{. 9 7}$ \\
\hline
\end{tabular}




\begin{tabular}{lllll}
\hline AGFI & $.90 \leq \mathrm{AGFI} \leq 1.00$ & $.85 \leq \mathrm{AGFI}<.90$ & $\mathbf{. 8 6}$ & $\mathbf{. 9 4}$ \\
\hline NFI & $.95 \leq \mathrm{NFI} \leq 1.00$ & $.90 \leq \mathrm{NFI}<.95$ & $\mathbf{. 9 0}$ & $\mathbf{. 9 5}$ \\
& & & & $\mathbf{. 9 5}$ \\
\hline TLI & $.90 \leq \mathrm{TLI} \leq 1.00$ & $.85 \leq \mathrm{TLI}<.90$ & $\mathbf{. 9 2}$ & $\mathbf{. 9 6}$ \\
\hline RMSEA & $.00 \leq$ RMSEA $\leq .05$ & $.05<$ RMSEA $\leq .10$ & $\mathbf{. 0 6}$ & $\mathbf{. 0 6}$ \\
\hline
\end{tabular}

Ölçeklere ilişkin uyum indeksleri incelendiğinde bütün değerlerin kabul edilebilir/mükemmel uyum gösterdiği görülmektedir. Ortaya çıkan ilişki düzeylerinin açılanmasında regresyon analizinden yararlanılmıştır. Regresyon analizi farklı programlar aracılığı ile gerçekleştirilen birincil nesil veri analizi yöntemi olmakla birlikte araştırmada gözlenen değişkenler ile örtük değişkenler arasındaki ilişkilerin bir arada bulunduğu ve birçok yöntemin kullanılabildiği karmaşık modellerin sistematik bir şekilde ele alındığı ve en önemlisi birinci nesil analizlerde göz ardı edilen dolaylı etkileri de içerisine alan ikinci nesil veri analiz yöntemi olarak kullanılan yapısal eşitlik modelinin kullanılmasına karar verilmiştir (Anderson ve Gerbing, 1988). Bu doğrultuda araştırmada kurulan modellere ilişkin regresyon analiz sonuçları Tablo 2'de verilmiştir.

\section{Kurulan Modellere İlişkin Yapısal Eşitlik Analizi Bulguları}

\section{Model 1}

H1: Serbest zaman doyumu mutluluğu anlamlı ve pozitif olarak etkiler.

Model 1 (H1) için kurulan hipotezin test edilmesi için yapısal eşitlik analizi yapılmıştır. Gerçekleştirilen analiz sonuçları ve yol diyagramı aşağıda sunulmuştur.

Tablo 2- Yapısal Eşitlik Modeline İlişkin (Model 1-H1) Regresyon Katsayısı

\begin{tabular}{|c|c|c|c|c|}
\hline Değisskenler & $\beta$ & $S_{h}$ & $\begin{array}{l}\mathrm{T} \text { (kritik } \\
\text { oran) }\end{array}$ & $\mathbf{P}$ \\
\hline $\begin{array}{c}\text { Serbest Zaman Doyumu (psikolojik) } \\
\text { Mutluluk }\end{array}$ & .234 & .277 & .842 & .400 \\
\hline $\begin{array}{c}\text { Serbest Zaman Doyumu (eğitimsel) } \\
\text { Mutluluk }\end{array} \longrightarrow$ & -.306 & .295 & -1.036 & .300 \\
\hline $\begin{array}{l}\text { Serbest Zaman Doyumu (sos } \\
\text { Mutluluk }\end{array}$ & .115 & .084 & 1.373 & .170 \\
\hline $\begin{array}{c}\text { Serbest Zaman Doyumu (fiziksel) } \\
\text { Mutluluk }\end{array}$ & .038 & .067 & .559 & .576 \\
\hline $\begin{array}{c}\text { Serbest Zaman Doyumu (rahatlama) } \\
\text { Mutluluk }\end{array}$ & .152 & .075 & 2.018 & $* * *$ \\
\hline $\begin{array}{l}\text { Serbest Zaman Doyumu (estedik) } \\
\text { Mutluluk }\end{array}$ & .145 & .058 & 2.517 & $* * *$ \\
\hline
\end{tabular}

*** $\mathrm{p}<0.001$

Tablo 2' de kurulan modele ilişkin regresyon katsayısı, standart hata ve kritik oran ve p değeri yer almaktadır. Bulgulara göre serbest zaman doyumu (rahatlama) ile mutluluk arasında nedensel ilişkinin olduğu $(\beta=.152$. $p<0.001)$ ve $p$ değerinin istatistiksel olarak anlamlı $(p<$ 
0.001) olduğu bulgusuna ulaşılmıştır. Bu durum değerlendirildiğinde serbest zaman doyumu (rahatlama) değişkeninin mutluluk üzerinde anlamlı ve pozitif etkisinin olduğu söylenebilir. Aynı şekilde serbest zaman doyumu (estetik) ile mutluluk arasında nedensel ilişkinin olduğu $(\beta=.145 . p<0.05)$ ve $p$ değerinin istatistiksel olarak anlamlı $(p<0.05)$ olduğu bulgusuna ulaşılmıştır. Bu durum değerlendirildiğinde serbest zaman doyumu (estetik) değişkeninin mutluluk üzerinde anlamlı ve pozitif etkisinin olduğu söylenebilir.

\section{Şekil 2- Model 1' e ait Yol Diagramı}

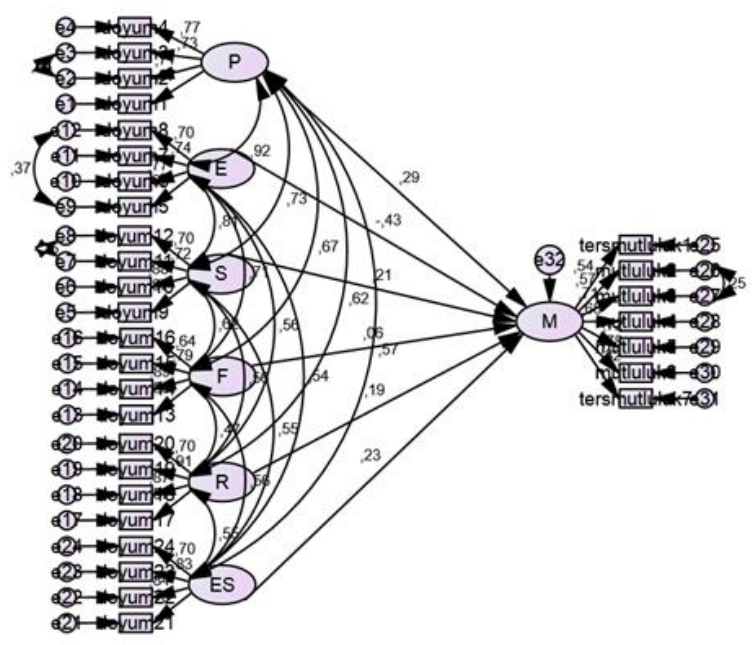

Tablo 3- Standart Uyum İndeksleri ve Model 1'e İlişkin Uyum İndeksleri (Schumacher ve

Lomax, 1996; Schermelleh, Engel ve Moosbrugger, 2003: 23-74)

\begin{tabular}{ccccc}
\hline Uyum İndeksi & Mükemmel Uyum & Kabul Edilebilir Uyum & & Model 1-H1 \\
\hline $\mathbf{x}^{2} / \mathrm{sd}$ & $0-3$ & $3-5$ & $\mathbf{2}$ & Kabul edilebilir uyum \\
\hline CFI & $.95 \leq \mathrm{CFI} \leq 1.00$ & $.90 \leq \mathrm{CFI}<.95$ & $\mathbf{. 9 2}$ & Mükemmel uyum \\
\hline GFI & $.90 \leq \mathrm{GFI} \leq 1.00$ & $.85 \leq \mathrm{GFI}<.90$ & $\mathbf{. 8 6}$ & Mükemmel uyum \\
\hline AGFI & $.90 \leq \mathrm{AGFI} \leq 1.00$ & $.85 \leq \mathrm{AGFI}<.90$ & $\mathbf{. 8 5}$ & Kabul edilebilir uyum \\
\hline NFI & $.95 \leq \mathrm{NFI} \leq 1.00$ & $.90 \leq \mathrm{NFI}<.95$ & $\mathbf{. 8 6}$ & Kabul edilebilir uyum \\
\hline TLI & $.90 \leq \mathrm{TLI} \leq 1.00$ & $.85 \leq \mathrm{TLI}<.90$ & $\mathbf{. 9 1}$ & Mükemmel uyum \\
RMSEA & $.00 \leq \mathrm{RMSEA} \leq .05$ & $.05<$ RMSEA $\leq .10$ & $\mathbf{. 0 5}$ & Kabul edilebilir uyum \\
\hline
\end{tabular}

Modele ilişkin uyum indeksleri incelendiğinde bütün değerlerin kabul edilebilir/mükemmel uyum gösterdiği ve kurulan modelin istatistiksel olarak anlamlı çıkması modelin (Model 1H1) doğrulandığını yani kabul edildiğini göstermiştir.

Araştırmada "serbest zaman doyumu-estetik" ile "mutluluk" arasında; "serbest zaman doyumu-rahatlama" ile "mutluluk" arasında nedensellik ilişkisinin bulunması bu değişkenler ile "cinsiyet" değişkenin düzenleyici etkisi olup olmadığı problemini akla getirmiştir. Bu nedenle araştırmada tüm bu ilişkilerde "cinsiyet" değişkeninin bir düzenleyicilik rolü olup 
olmadığ1 araştırılmıştır. Bunun için model (Model 2-H2) öncelikle kadın ve erkekler için ayrı ayrı analiz edilmiştir.

\section{Model 2}

H2: Serbest zaman doyumunun mutluluğa etkisi cinsiyete bağlıdır. Bu etki kadınlarda erkeklere oranla daha düşüktür.

Model 2 (H2) için kurulan hipotezin test edilmesi için yapısal eşitlik analizi yapılmıştır. Gerçekleştirilen analiz sonuçları ve yol diyagramı aşağıda sunulmuştur.

Tablo 4- Değişkenler arasındaki ilişkilerde çoklu grup karşılaştırma sonuçları (Model 2-H2)

\begin{tabular}{|c|c|c|c|c|c|c|c|c|c|c|}
\hline & \multicolumn{2}{|c|}{ Kadın } & \multicolumn{2}{|c|}{ Erkek } & \multicolumn{3}{|c|}{ Kadın } & \multicolumn{3}{|c|}{ Erkek } \\
\hline $\begin{array}{c}\text { Düzenleyici değişken }(\mathrm{W}) \\
\text { cinsiyet. } \\
\text { Tahmin değişkeni }(\mathrm{X}) \\
\text { serbest zaman doyumu. } \\
\text { Sonuç değişkeni }(\mathrm{Y}) \\
\text { mutluluk olarak } \\
\text { alınmıştır. }\end{array}$ & $\beta$ & $S_{h}$ & $\beta$ & $S_{h}$ & $\begin{array}{c}\mathrm{T} \\
\text { (kritik } \\
\text { oran) }\end{array}$ & $\mathbf{P}$ & Label & $\begin{array}{c}\mathrm{T} \\
\text { (kritik } \\
\text { oran) }\end{array}$ & $\mathbf{P}$ & Label \\
\hline $\begin{array}{c}\text { ESTETIK } \\
\text { Serbest Zaman Doyumu } \\
\text { (estetik) } \longrightarrow \text { Mutluluk }\end{array}$ & .198 & .047 & .228 & .080 & 4.266 & $* * *$ & $\mathrm{a}$ & 2.846 & $* * *$ & $\mathbf{b}$ \\
\hline $\begin{array}{l}\text { KADIN-RAHATLAMA } \\
\text { Serbest Zaman Doyumu } \\
\text { (rahatlama) } \\
\text { Mutluluk }\end{array}$ & .196 & .046 & .214 & .074 & 4.271 & $* * *$ & a & 2.903 & .004 & $\mathbf{b}$ \\
\hline
\end{tabular}

Tablo 4'te kurulan modele ilişkin regresyon katsayısı, standart hata ve kritik oran ve p değeri yer almaktadır. Analiz sonuçları incelendiğinde "serbest zaman doyumu-estetik ile mutluluk" ilişkisinde (erkekler için $\beta=.228$ kadınlar için $\beta=.198 p<0.001$ ) ve "serbest zaman doyumurahatlama ile mutluluk" ilişkisinde (erkekler için $\beta=.214$ kadınlar için $\beta=.196 p<0.001$ ) kadın ve erkekler açısından anlamlı farklılıkların olduğu belirlenmiştir. Buna göre erkeklerin gerçekleştirdikleri serbest zaman etkinliğinde estetik doyum ve rahatlama düzeyleri arttıkça kadınlara göre daha fazla mutlu oldukları belirlenmiştir.

Şekil 3-Model 2' e ait Yol Diagramı (KADIN (YOL= a). ESTETIK)
Şekil 4-Model 2' e ait Yol Diagramı (ERKEK (YOL=a). ESTETIK) 


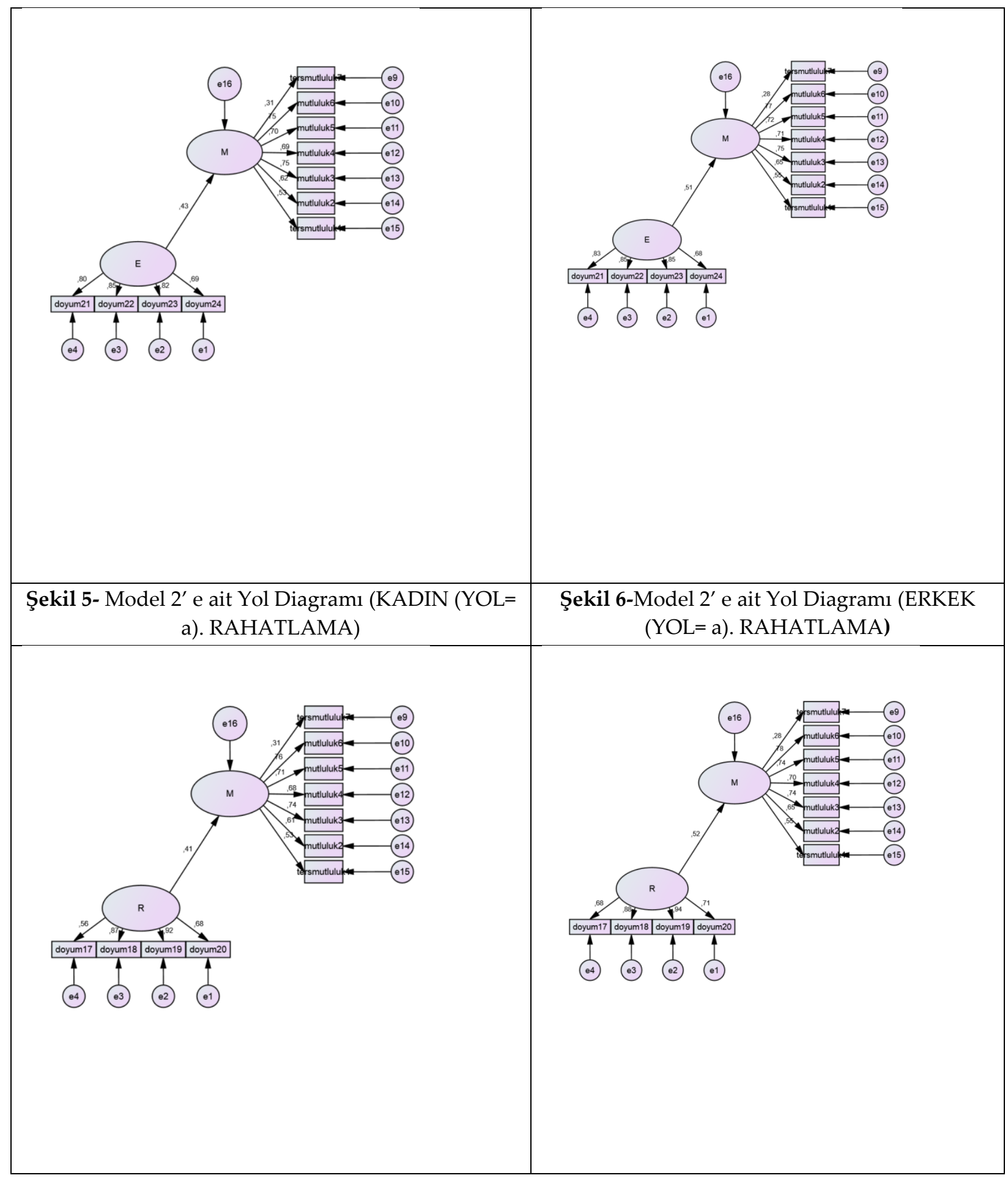

Tablo 5- Standart Uyum İndeksleri ve Model 1'e İlişkin Uyum İndeksleri (Schumacher ve Lomax. 1996; Schermelleh. Engel ve Moosbrugger. 2003: 23-74)

\begin{tabular}{ccccccc}
\hline $\begin{array}{c}\text { Uyum } \\
\text { Indeksi }\end{array}$ & $\begin{array}{c}\text { Mükemmel } \\
\text { Uyum }\end{array}$ & $\begin{array}{c}\text { Kabul Edilebilir } \\
\text { Uyum }\end{array}$ & $\begin{array}{c}\text { Model 2-H2 } \\
\text { KADIN- } \\
\text { ESTETiK }\end{array}$ & $\begin{array}{c}\text { Model 2-H2 } \\
\text { ERKEK- } \\
\text { ESTETiK }\end{array}$ & $\begin{array}{c}\text { Model 2-H2 } \\
\text { KADIN- } \\
\text { RAHATLAMA }\end{array}$ & $\begin{array}{c}\text { Model 2-H2 } \\
\text { ERKEK- } \\
\text { RAHATLAMA }\end{array}$ \\
\hline $\mathrm{x}^{2} / \mathrm{sd}$ & $0-3$ & $3-5$ & $\mathbf{1}$ & $\mathbf{1}$ & $\mathbf{2}$ & $\mathbf{2}$ \\
\hline $\mathrm{CFI}$ & $.95 \leq \mathrm{CFI} \leq 1.00$ & $.90 \leq \mathrm{CFI}<.95$ & .96 & .96 & .94 & .94 \\
\hline
\end{tabular}




\begin{tabular}{ccccccc}
\hline GFI & $.90 \leq \mathrm{GFI} \leq 1.00$ & $.85 \leq \mathrm{GFI}<.90$ & .94 & .94 & .92 & .92 \\
\hline AGFI & $.90 \leq \mathrm{AGFI} \leq 1.00$ & $.85 \leq \mathrm{AGFI}<.90$ & .91 & .91 & .89 & .89 \\
\hline NFI & $.95 \leq \mathrm{NFI} \leq 1.00$ & $.90 \leq \mathrm{NFI}<.95$ & .92 & .92 & .91 & .91 \\
\hline TLI & $.90 \leq \mathrm{TLI} \leq 1.00$ & $.85 \leq \mathrm{TLI}<.90$ & .95 & .95 & .93 & .93 \\
\hline RMSEA & $.00 \leq \mathrm{RMSEA} \leq .05$ & $.05<\mathrm{RMSEA} \leq .10$ & .04 & .04 & .05 & .05 \\
\hline
\end{tabular}

Modele ilişkin uyum indeksleri incelendiğinde de bütün değerlerin kabul edilebilir/mükemmel uyum gösterdiği ve kurulan modelin istatistiksel olarak anlamlı çıkması modelin (Model 2-H2) doğrulandığını yani kabul edildiğini göstermiştir.

\section{Tartışma ve Sonuç}

Araştırmada doğada gerçekleştirilen rekreatif etkinliklere katılarak serbest zaman deneyimi yaşayan yerli turist katılımcıların etkinlikler sonucunda elde edecekleri doyumun mutluluk üzerindekisi ortaya çıkarılarak bu ikili ilişkide ayrıca cinsiyet değişkeninin düzenleyici rolü olup olmadığı araştırılmıştır. Elde edilen sonuçlar, katılımcıların serbest zaman doyum ölçeğinin "rahatlama" ve "estetik" alt boyutları ile "mutluluk" üzerinde etkisinin olduğu diğer alt boyutların mutluluk üzerinde bir etkisinin olmadığ tespit edilmiştir (Tablo 2). Bu durum değerlendirildiğinde katılımcıların deneyim sonucu elde ettikleri doyumun estetik ve rahatlama olarak ortaya çıktığı ve bunun da mutluluk üzerinde bir etki gösterdiği ifade edilebilir. Katılımcıların gerçekleştirdikleri etkinlik deneyimine ilişkin estetik ve rahatlama açısından doyum düzeylerinin artmaları etkinlik sonucunda elde edilecek mutluluk düzeyini de arttıracaktır. Bu da bireyin katıldığı etkinlik sonucunda kendisini daha mutlu hissetmesini sağlayacaktır. Etki durumunun cinsiyet üzerinde nasıl bir farklılaşma yaratacağını belirlemek amaciyla serbest zaman doyumunun mutluluk üzerindeki etkisinde cinsiyet değişkeninin düzenleyici rolü araştırılmıştır. Elde edilen sonuçlar, katılımcıların serbest zaman doyum ölçeğinin "rahatlama" ve "estetik" alt boyutları ile "mutluluk" üzerinde düzenleyici etkisinin olduğu tespit edilmiştir (Tablo 4). Bu durum değerlendirildiğinde katılımcıların serbest zaman deneyimleri sonucu elde ettikleri "estetik" ve "rahatlama" doyum düzeylerinin mutluluk üzerindeki etkisinde erkek katılımcıların kadın katılımcılara göre daha fazla olduğu; deneyim sonucu artan estetik doyum ve rahatlamanın erkek katılımcıları daha fazla mutlu ettiği sonucuna varılmıştır. Bu sonuçlar değerlendirildiğinde bu tür etkinliklerde aslında yaratılışları gereği kadınların erkeklere göre daha fazla estetik şeylere dikkat etmeleri beklenmektedir. Ancak sonuçlar tam tersini vermektedir. Şöyle ki bu sonuçların bu şekilde ortaya çıkmasındaki en büyük etken, kadınların hayatın her alanında olduğu gibi serbest zamanlarını değerlendirmelerinde de birtakım kısıtlamalara maruz bırakılmalarıdır. Kadınlar kendileri için ayıracakları zaman dilimlerinde rekreatif bir etkinliğe katılım göstermek yerine zamanlarının çoğunu ev işleri, alışveriş, çocuk bakımı gibi işlere harcamaktadır. Bunun dışında bazı katılımcılarda bu tür etkinliklere katılım göstermek isteseler bile maalesef toplum tarafından bir takım fiziksel ve psikolojik engellere maruz kalmaktadır (Kelly, 1990; Waren, 1990; Henderson, 1990; Müderrissoğlu, 2005). 
Literatür incelendiğinde genel olarak "farklılıkların belirlenmesine" yönelik çalışmalar yapılmış ve bu çalışmalarda serbest zaman doyumuna ilişkin alt boyutlar açısından farklılıklar tespit edilemezken genel ölçek ortalama puanları açısından erkek katılımcıların doyum puan ortalamalarının kadın katılımcılara göre daha yüksek olduğu belirlenmiştir (Ardahan ve Yerlisu Lapa, 2010; Aydın, 2016). Diğer taraftan serbest zaman doyumuna ilişkin "rahatlama" alt boyutunda kadınların erkeklere göre daha yüksek puan ortalamasına sahip olduğu çalışmalara rastlanırken (Gökçe, 2008; Küçük Kılıç, Lakot Atasoy, Gürbüz ve Öncü, 2016); mevcut araştırma bulgularını destekler nitelikte "rahatlama" ve "estetik" alt boyutunda erkek katılımcıların daha yüksek puan ortalamasına sahip olduğu çalışmalarda bulunmaktadır (Doğan, Elçi ve Gürbüz, 2019).

Literatürde serbest zaman doyumu ile mutluluk ile ilgili çalışmalar incelendiğinde; katılımcıların seçtikleri serbest zaman etkinliklerine ilişkin deneyimlerinin sonucunda doyuma ulaştıkları ve bunun sonucunda mutlu oldukları belirlenmiştir (Andrew ve Withey, 1976; Lu ve Argyle, 1993-1994; Kim ve Heo, 2014; Lin, Chen ve Kuo, 2014). Benzer şekilde serbest zaman etkinliklerine katılan bireylerin etkinlik deneyimi sonucunda elde ettikleri içsel hazzın bireylerin mutluluk düzeyi üzerinde etkisi olduğu ifade edilmiştir ( $\mathrm{Lu}$ ve $\mathrm{Hu}, 2002$; Bailey ve Fernando (2012). Andrew ve Withey (1976) yılında yaptıkları çalışmada serbest zaman deneyimi sonucunda katılımcıların büyük bir çoğunluğunun doyuma ulaştığı ve bunun sonucunda mutlu oldukları yalnızca küçük bir kesimin olumsuz deneyimler yaşadıkları ve bu durumun onları mutsuz ettiği ifade edilmiştir. Literatürde katılımcıların tatil öncesi ve tatil sonrası doyum ve mutluluk düzeylerini inceleyen çalışmalara da rastlanılmıştır. Özellikle tatil süresince serbest zaman etkinliklerine katılarak deneyim yaşayan katılımcıların tatil bitiminde yüksek seviyede doyuma ulaşarak mutlu bir şekilde eve dönüş yaptıkları ve tatil sonrasında anıların hatırlanmasının mutluluğu arttıracağı ifade edilmiştir (Milman, 1998; Bloom, Geurts, Taris, Sonnentag, Weerth ve Kompier, 2010; Nawijn ve Peeters, 2010; McCabe ve Johnson, 2013; Avcıkurt, 2015).

Literatürde yer alan çalışmalar ve mevcut araştırma sonuçları değerlendirildiğinde bir tutarlılı̆̆ın söz konusu olduğu söylenebilir. Doğada gerçekleştirilen serbest zaman etkinliklerine katılan bireylerin etkinlik deneyimi sonucunda pozitif çıktılara ulaştığ söylenebilir. Bu durumun bireylerin doyum düzeylerinin artmasında ve doğrudan mutluluk düzeyine etki ettiği sonucuna varılabilir. Ancak çalışmanın odak noktasının cinsiyet faktörü olduğu düşünüldüğünde deneyim sonucunda özellikle kadınların estetik, güzellik vb. konulara daha dikkat etmeleri açısından etkinliklere yönelik sonuçlara da yansıyacağı düşünülürken; erkeklerin kadınlara oranla daha fazla "estetik ve rahatlama doyum düzeyine ulaşarak mutlu olmaları oldukça düşündürücüdür. Her ne kadar bu durum kadınların hayatın her alanında kısıtlamalara maruz bırakılmalarıyla bağdaştırılsa da ortaya çıkan sonuçların ileri de yapılacak çalışmalarda değerlendirilmesinde fayda vardır.

Sonuç olarak bireylerin kendileri için ayırdıkları zaman dilimlerinde serbest zaman deneyimleri yaşamaları ve bu deneyimi sürdürülebilir hale getirmeleri katılımcıların daha mutlu bir hayat sürmelerinde etken olacağı düşünülmektedir. Mevcut araştırma sonuçları ve literatürde yer alan sonuçlar bunu destek niteliktedir. 


\section{Öneriler}

Literatürde doğada gerçekleştirilen rekreatif etkinliklere katılım konusunda gerçekleştirilen çalışmaların kısıtlı olduğu görülmüştür. Özellikle rekreasyon ve turizmin iç içe olduğu özel bir alan olan doğa ve macera rekreasyonlarına ilişkin etkinlik deneyimiyle ilgili çalışmalara yoğunluk verilmesi bu alanın önünü açacaktır. Ayrıca yapılacak çalışmalarda eşit koşullar altında yer alan katılımcıların seçilerek doyum, mutluluk ve cinsiyet faktörü üzerinde durulmasının literatürde yer tartışmalara katkı sağlayacaktır.

\section{Kaynakça}

Aslan, Z. (1993). Sanayileşme ve kentleşmenin doğada rekreasyon faaliyetlerine duyulan gereksinimi arttırıcı etkisi, Ekoloji ve Çevre Dergisi, 2(8), 22-24.

Anderson, J. C., \& Gerbing, D. W. (1988). Structural equation modeling in practice: A review and recommended two-step approach. Psychological bulletin, 103(3), 411.

Ardahan F. (2003). Turizmde Franchising ve Türk evi pansiyonları franchising model önerisi ve uygulaması, Selçuk Üniversitesi Sosyal Bilimler Enstitüsü (Doktora Tezi, Konya). Erişim adresi: $\underline{\text { http://tez2.yok.gov.tr/ }}$

Ardahan, F. \& Yerlisu Lapa, T. (2010). Üniversite öğrencilerinin serbest zaman tatmin düzeylerinin cinsiyete ve gelire göre incelenmesi. Spor Bilimleri Dergisi, 21(4), 129-136.

Aydın, İ. (2016). Fitness Katılımcılarının rekreasyonel etkinliklere yönelik ilgilenim ve mutluluk düzeylerinin belirlenmesi, Gazi Üniversitesi Sağlık Bilimleri Enstitüsü, (Yüksek Lisans Tezi,Ankara). Erişim adresi: http://tez2.yok.gov.tr/

Andrew, F.M. \& Withey, S.B. (1976). Social Indicators of Well-Being (Plenum, New Y.)

Avcıkurt, C. (2015). Turizm Sosyolojisi - Genel ve Yapısal Yaklaşım. (4. Baskı). Ankara: Detay Yayıncilık.

Baud-Bovy, M. \& Lawson, F. (1998). Tourism and Recreation Handbook of Planning and Design. Oxford: Architecrural Press.

Bell, S. (2001). Design for Outdoor Recreation Second Edition, Midas Printing, China.

Beard, J.G. \& Ragheb, M.G. (1980). Measuring leisure satisfaction. Journal of Leisure Research, 12(1), 20-33.

Bailey, A.W. \& Fernando, I.K. (2012). Routine and project-based leisure, happiness, and meaning in life. Journal of Leisure Research, 44(2), 139-154. Doi: https://doi.org/10.1080/00222216.2012.11950259

Bloom, J.D., Geurts, S.A.E., Taris, T.W., Sonnentag, S., Weerth, C.D. \& Kompier, M.A.J. (2010). Effects of Vacation from Work on Health and Well-Being: Lots off, Quickly Gone, Work \& Stress: An International Journal of Work. Health E Organisations, 24(2), 196-216.Doi: https://doi.org/10.1080/02678373.2010.493385

Csikszentmihalyi, M. (2005). Akış Mutluluk Bilimi, çev. Sema Kunt Akbaş, HYB yayıncılık, Ankara. 
Doğan, T., \& Çötok, N. A. (2016). Oxford mutluluk ölçeği kısa formunun Türkçe uyarlaması: Geçerlik ve güvenirlik çalışması. Türk Psikolojik Danışma ve Rehberlik Dergisi, 4(36).

Elçi, G., Doğan, M., \& Gürbüz, B. (2019). Bireylerin rekreasyonda algılanan sağlık çıktıları ve yaşam doyumu düzeylerinin incelenmesi. Uluslararası Spor Egzersiz ve Antrenman Bilimi Dergisi, 5(3), 93-106.

Gökçe, H., (2008). Serbest zaman doyumunun yaşam doyumu ve sosyo demografik değişkenler açısından incelenmesi, Pamukkale Üniversitesi Sağlık Bilimleri Enstitüsü, (Yüksek Lisans Tezi, Denizli).

Gökçe, H., \& Orhan, K. (2011). Serbest zaman doyum ölçeğinin Türkçe geçerlilik güvenirlik çalışması. Spor Bilimleri Dergisi, 22(4), 139-145.

Hacıoğlu, N., Gökdeniz, A. \& Dinç, Y. (2003). Boş Zaman ve Rekreasyon Yönetimi, Örnek Animasyon Uygulamaları. Ankara: Detay Yayıncılık.

Henderson, K.A. (1990) Anatomy is not destiny: A feminist analysis of the scholarship on women's leisure. Leisure Sciences, 12, 229 - 236.

Hills, P., \& Argyle, M. (2002). The Oxford Happiness Questionnaire: a compact scale for the measurement of psychological well-being. Personality and individual differences, 33(7), 10731082.

Kelly, J.R. (1990). Leisure. Prentice Hall. Englewood Clieffs. New Jersey.

Kılbaş, Ş. (2001). Rekreasyon-Boş Zamanı Değerlendirme. Adana: Anaca Yayınları.

Kim, J. \& Heo, J.(2014). Health benefits of serious involvement in leisure activities among older korean adults. International Journal of Qualitiative Studies on Health and Well-being, 9, 1-9.

Küçük Kılıç S., Lakot Atasoy K., Gürbüz B. ve Öncü E. (2016). Rekreasyonel Tatmin ve Yaşam Doyumu Arasındaki İlişkinin İncelenmesi, İstanbul Üniversitesi Spor Bilimleri Dergisi, 6;5670.

Lin, H.C., Chen, K.Y. \& Kuo, K.P. (2014). Relationship between leisure involvement and subjective well-being: moderating effect of spousal support. South African Journal for Research in Sport, Physical Education and Recreation, 36(1), 131-146.

Lu, L. \& Hu, C.H. (2002). Experiencing leisure: The case of Chinese university students, Fu Jen Studies: Science and Engineering 36, 1-21.

Lu, L. \& Argyle, M. (1993). TV watching, soap opera and happiness. Kaohsiung Journal of Medical Sciences 9, 350-360.

Lu, L. \& Argyle, M. (1994). Leisure satisfaction and happiness as a function of leisure activity, Kaohsiung Journal of Medical Sciences 10, 89-96.

Luetkens, S.A. (2004). The Integration of Physical Activity and Social Youth Work Common Goals and Synergy Effects of Two Discrete Social System. International Conference on Leisure, Tourism \& Sport-Education, Integration, Innovation, Cologne: Germany (18-21).

Milman, A. (1998). The Impact of tourism and travel experience on senior travelers' psychological well-being. journal of Travel Research, 37 (2), 166-170.

Marar, Z. \& Çağlayan, S. (2004). Mutluluk paradoksu: Özgürlük ve onaylanma. Kitap Yayınevi. 
McCabe, S. \& Johnson, S. (2013). The happiness factor in tourism: subjective well-being and social tourism. Annals of Tourism Research, 41, 42-65.

Müderrisoğlu, H., Kutay. E.L. \& Örnekçi Eşen, S. (2005). Kırsal rekreasyonel faaliyetlerde kısıtlayıcılar. Tarım Bilimleri Dergisi. 11(1), 40-44.

Moore, K., Cushman, G. \& Simmons, D. (1995). Behavioral conceptualization of tourism and leisure. Annals of Tourism Research, 22(1), 67-85.

Nawijn, J. \& Peeters, P. M. (2010). Travelling 'Green': is Tourists' Happiness at Stake?. Current Issues in Tourism, 13 (4), 381-392.

Schermelleh, E. K., Moosbrugger, H. (2003). Evaluating the fit of structural equation models: tests of significance and descriptive goodness-of-fit measures. Methods Of Psychological Research Online, 8 (2): 23-74.

Schumacher, R. E., Lomax, R. G. (1996). A Beginner's Guide to Structural Equation Modeling. New Jersey: Lawrence Erlbaum Associates, Publishers.

Tangeland, T. \& Aas, Ø. (2011). Household composition and the importance of experience attributes of natu Weber, K. (2001). Outdoor adventure tourism a review of research approaches. Annals of Tourism Research, 28(2), 360-377.

Veenhoven, R. (2000). Freedom and happiness: A comparative study in forty-four nations in the early 1990s. Culture and subjective well-being, 257-288.

Warren, K. (1990) Women's outdoor adventures, In Miles. J. C. \& Priest. S. (Eds.). Adventure Education ss.411-417. State College. PA: Venture. 